\title{
QSAR for Binding Affinity of Substituted Dibenzoylhydrazines to Intact Sf-9 Cells
}

\author{
Takehiko Ogura, Yoshiaki NaKagawa, ${ }^{*}$ Chieka MinaKuchi ${ }^{\dagger}$ and Hisashi MiYagawa \\ Division of Applied Life Sciences, Graduate School of Agriculture, Kyoto University, Kyoto 606-8502, Japan
}

(Received May 18, 2004; Accepted August 2, 2004)

\begin{abstract}
The binding affinity to intact Sf-9 cells was measured in a series of $N$ - $t$-butyl- $N, N^{\prime}$-dibenzoylhydrazine congeners. The benzene ring close to the $t$-butyl group of the compounds was substituted with $\mathrm{Cl}$ at the ortho-position and the other benzene ring was variously substituted at the para-position. The effects of the substituent on the binding affinity were analyzed quantitatively using the Hansch-Fujita QSAR method. The introduction of hydrophobic and electron-donating substituents at the para-position enhanced the binding affinity toward the ecdysone receptor protein. Steric repulsion between the substituent and receptor surface was also suggested. (C) Pesticide Science Society of Japan
\end{abstract}

Keywords: QSAR, dibenzoylhydrazines, Sf-9 cells, Spodoptera frugiperda, ecdysone agonists, ponasterone A.

\section{INTRODUCTION}

Certain $N$ - $t$-butyl- $N, N^{\prime}$-dibenzoylhydrazine (DBH) analogs (DBHs, Fig. 1) show strong insecticidal activity ${ }^{1)}$ by binding to the receptor of the insect molting hormone, 20-hydroxyecdysone (Fig. 1). ${ }^{2,3)}$ Some DBHs such as tebufenozide (Fig. 1: $\left.\mathrm{X}_{n}=3,5-\left(\mathrm{CH}_{3}\right)_{2}, \mathrm{Y}_{n}=4-\mathrm{C}_{2} \mathrm{H}_{5}\right),{ }^{4)}$ methoxyfenozide (Fig. 1: $\left.\mathrm{X}_{n}=3,5-\left(\mathrm{CH}_{3}\right)_{2}, \mathrm{Y}_{n}=2-\mathrm{CH}_{3}-3-\mathrm{OCH}_{3}\right),{ }^{5}$ chromafenozide (Fig. $1)^{6}$ ) and halofenozide (Fig. 1: $\mathrm{X}_{n}=\mathrm{H}, \mathrm{Y}_{n}=4-\mathrm{Cl}$ ) ${ }^{7}$ are available on the market to control lepidopteran and other pest insects. Since these compounds target the molting and metamorphosis of insects, they are considered harmless to vertebrates. ${ }^{8)}$ In addition, because these insecticides are safe to aquatic organisms and beneficial insects, they are environmentally and ecologically acceptable as part of an integrated pest management (IPM) program. ${ }^{9)}$

Previously, we measured larvicidal activities of various series of DBHs in two lepidopteran species, the rice stem borer Chilo suppressalis ${ }^{10,11)}$ and the beet armyworm Spodoptera exigua, ${ }^{12,13)}$ as well as the coleopteran Colorado potato beetle Leptinotarsa decemlineata. ${ }^{14,15}$ The relationship of larvicidal potency to the substitution pattern on two benzene rings of DBHs was similar for the activities against two lepidopteran

\footnotetext{
* To whom correspondence should be addressed. E-mail: naka@kais.kyoto-u.ac.jp

$\dagger$ Present address: Department of Biology, University of Washington, 24 Kincaid Hall, Box 351800, Seattle, WA 98195-1800, USA

CPesticide Science Society of Japan
}

insect species, but entirely different for activities against lepidopteran and coleopteran insects. Effects of substituents at the A- and B-rings of DBHs (Fig. 1) on the larvicidal potency were analyzed quantitatively using the Hansch-Fujita QSAR method. ${ }^{10-15)}$ The QSAR results reinforced clearly the above described similarity in larvicidal activity among the same insect orders and difference between different insect orders in terms of physicochemical effects. These structure-activity studies are useful for elucidating the structures of potent larvicides.

The aim of the present study is to clarify essential physicochemical properties of DBHs in ligand-receptor binding using the QSAR method. The interaction with isolated receptor protein is considered to reflect the intrinsic biological activity. With the use of receptor proteins, one could expect ligand-receptor binding without the physiological events such as metabolism, excretion, and membrane transportation involved under larvicidal test conditions. Interestingly, however, we previously demonstrated that intact cells of certain cell lines, such as Sf-9 cells established from the ovaries of the fall armywarm Spodoptera frugiperda, are utilizable as a substitute of the isolated ecdysone receptor protein. ${ }^{16)}$ In other words, the processes involved in the transport of compounds from outside the cell to the receptor sites were indicated as being not critical in this assay system. In this study, we measured the Sf-9 cell binding of a series of ortho-chlorobenzoyl analogs of DBH with various substituents at the para-position of the B-ring (Fig. 1, $\mathrm{X}_{n}=2-\mathrm{Cl}$ ). We quantitatively analyzed the substituents' effects on the binding affinity using physicochemical parameters. 


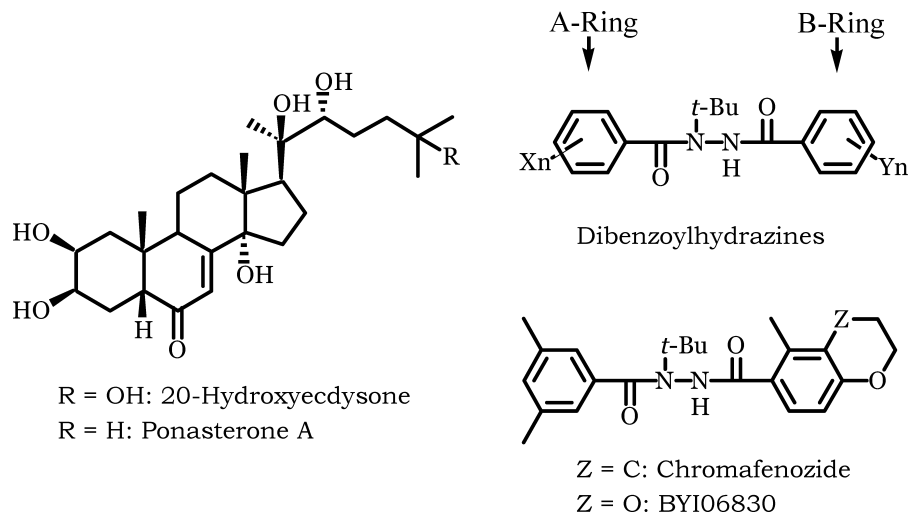

Fig. 1. Structures of ecdysteroids and diacylhydrazines.

\section{MATERIALS AND METHODS}

\section{Chemicals}

Eighteen DBHs with various substituents at the para-position of the B-ring, but with the A-ring substituent fixed as 2-Cl, were subjected to binding assays (Table 1). Compounds 1-12 and 14-18 are from our previous studies..$^{10,14)}$ Compound $\mathbf{1 3}$ was newly synthesized, $\mathrm{mp} .110 .5-111.0^{\circ} \mathrm{C}$. Its structure was confirmed by NMR and an elemental analysis for $\mathrm{C}, \mathrm{H}$ and $\mathrm{N}$ which agreed with the calculated values within a range of $\pm 0.3 \%$. Ponasterone A (PonA, Fig. 1) was purchased from Invitrogen Corp. (Carlsbad, CA, USA) and $\left[{ }^{3} \mathrm{H}\right]$ PonA (5.55 TBq/mmol) was from American Radiolabeled Chemicals Inc. (St. Louis, MO, USA). The glass filter (GF/F, $\phi 25 \mathrm{~mm}$ ), was from Whatman International Ltd. (Maidstone, England), and Aquasol-2 (liquid scintillator) was from Packard Instrument Corp. (Meriden, CT, USA).

\section{Ligand Binding Assay}

The ligand binding assay was similar to that previously reported. ${ }^{17)}$ Briefly, $2 \mu$ l of $\left[{ }^{3} \mathrm{H}\right]$ PonA $(50,000-70,000 \mathrm{dpm})$ in an ethanol solution was added to a $\mathrm{Sf}-9$ cell suspension (400 $\mu \mathrm{l})$ with $1 \mu \mathrm{l}$ of compound at various concentrations in dimethyl sulfoxide (DMSO). DMSO (1 $\mu \mathrm{l})$ and $1.1 \mathrm{mM}$ PonA in ethanol $(1 \mu \mathrm{l})$ were added to prepare the negative and positive controls, respectively. After incubation for $30 \mathrm{~min}$ at $25^{\circ} \mathrm{C}$, reactions were terminated by rapid filtration through $\mathrm{GF} / \mathrm{F}$. The filter was transferred to a glass vial, and the radioactivity collected in the filter was measured in Aquasol-2 $(3 \mathrm{ml})$ with a liquid scintillation counter, Aloka LSC-1000 (Aloka Co., Ltd., Tokyo, Japan). Three runs were performed for each concentration.

The radioactivity collected in the filters was plotted against the reciprocal logarithm of the concentration of test compounds, and concentration-response curves were drawn. Each concentration-response curve was derived from responses at 8 concentrations including for DMSO (negative control) and PonA ( $2.6 \mu \mathrm{M}$, positive control). The maximum and minimum values of each curve were defined as values of
$0 \%$ and $100 \%$ inhibition of $\left[{ }^{3} \mathrm{H}\right]$ PonA binding, respectively. The concentration required to give the $50 \%$ inhibition value, $\mathrm{IC}_{50}(\mathrm{M})$, was evaluated using the probit transformation. ${ }^{18,19)}$ The $\mathrm{IC}_{50}$ measurement was replicated at least twice for each compound. We used $\mathrm{pIC}_{50}(\mathrm{M})$, the logarithm of reciprocal $\mathrm{IC}_{50}$, as the indicator of the binding affinity of test compounds.

\section{QSAR Analysis}

QSAR analysis was performed using the QREG system ver. 2.05. ${ }^{20)}$ The $\log$ P (P: partition coefficient in 1-octanol/ water system) value of compounds was either measured or calculated empirically as we previously reported. ${ }^{10,14)}$ Among various steric parameters, the STERIMOL width parameter $B_{1}$ was used. $B_{1}$ represents the minimum width of substituents in the projection on the plane perpendicular to the axis connecting the $\alpha$ atom of the substituents with the rest of the molecule. ${ }^{21,22)}$ In this analysis, $\Delta \mathrm{B}_{1}$, the value relative to that of hydrogen, was utilized. As the electronic parameter of substituents, the regular Hammett $\sigma$ value was used. ${ }^{22)}$

\section{RESULTS}

The binding affinity calculated from the concentration-response curve is listed in Table 1. The activity of the most potent compound (13: $\left.\mathrm{pIC}_{50}=8.27\right)$ is about 1000 times that of the least potent (18: 5.17) of the 18 test compounds. The introduction of alkyl groups is favorable to the activity (compounds 9-14), but that of polar substituents such as nitro (7), cyano (8), and methanesulfonyl (16) groups is not. Halogens are not as effective as alkyl groups.

The QSAR results for all compounds excluding the phenyl analog (18) are shown in Table 2 . The low collinearity among independent variables used to derive Eq. 3 is shown in Table 3. The statistical significance of the addition of the $\Delta \mathrm{B}_{1}$ term in Eq. 3 is not justified above the $95 \%$ level of significance. It is, however, above the $90 \%$ level so we took Eq. 3 as the QSAR equation to model the receptor binding. 
Table 1. Binding affinity of dibenzoylhydrazines to Sf-9 cells and physicochemical parameters

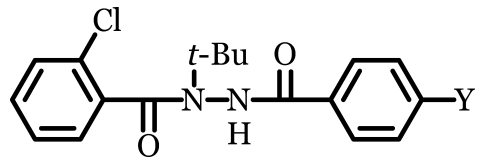

\begin{tabular}{|c|c|c|c|c|c|c|}
\hline \multicolumn{2}{|c|}{ Compounds } & \multicolumn{2}{|c|}{ Binding affinity $\left[\mathrm{pIC}_{50}(\mathrm{M})\right]$} & \multicolumn{3}{|c|}{ Physicochemical parameters } \\
\hline No & $\mathrm{Y}$ & Obsd. $^{a)}$ & Calcd. $^{b)}$ & $\log \mathrm{P}^{c)}$ & $\sigma^{d)}$ & $\Delta \mathrm{B}_{1}{ }^{d)}$ \\
\hline 1 & $\mathrm{H}$ & $7.08 \pm 0.13(4)$ & 7.08 & 2.59 & 0.00 & 0.00 \\
\hline 2 & $\mathrm{~F}$ & $7.29 \pm 0.08(2)$ & 7.07 & 2.87 & 0.06 & 0.35 \\
\hline 3 & $\mathrm{Cl}$ & $6.89 \pm 0.01(2)$ & 7.15 & 3.51 & 0.23 & 0.80 \\
\hline 4 & $\mathrm{Br}$ & $7.69 \pm 0.16(2)$ & 7.23 & 3.73 & 0.23 & 0.95 \\
\hline 5 & I & $7.30 \pm 0.09(2)$ & 7.34 & 3.96 & 0.18 & 1.15 \\
\hline 6 & $\mathrm{CF}_{3}$ & $6.96 \pm 0.06(2)$ & 6.93 & 3.68 & 0.54 & 0.99 \\
\hline 7 & $\mathrm{NO}_{2}$ & $6.42 \pm 0.01(2)$ & 6.29 & 2.78 & 0.78 & 0.70 \\
\hline 8 & $\mathrm{CN}$ & $5.74 \pm 0.09$ (3) & 6.22 & 2.44 & 0.66 & 0.60 \\
\hline 9 & $\mathrm{CH}_{3}$ & $7.28 \pm 0.06(2)$ & 7.36 & 3.15 & -0.17 & 0.52 \\
\hline 10 & $\mathrm{C}_{2} \mathrm{H}_{5}$ & $7.89 \pm 0.04(2)$ & 7.62 & 3.59 & -0.15 & 0.52 \\
\hline 11 & $n-\mathrm{C}_{3} \mathrm{H}_{7}$ & $7.64 \pm 0.03(2)$ & 7.88 & 4.06 & -0.13 & 0.52 \\
\hline 12 & $i-\mathrm{C}_{3} \mathrm{H}_{7}$ & $7.82 \pm 0.02(2)$ & 7.79 & 4.11 & -0.15 & 0.90 \\
\hline 13 & $n-\mathrm{C}_{4} \mathrm{H}_{9}$ & $8.27 \pm 0.07(2)$ & 8.24 & $4.60^{e)}$ & -0.16 & 0.52 \\
\hline 14 & $t-\mathrm{C}_{4} \mathrm{H}_{9}$ & $7.66 \pm 0.13(2)$ & 7.80 & 4.48 & -0.20 & 1.60 \\
\hline 15 & $\mathrm{OCH}_{3}$ & $7.21 \pm 0.04(2)$ & 7.31 & 2.82 & -0.27 & 0.35 \\
\hline 16 & $\mathrm{SO}_{2} \mathrm{CH}_{3}$ & $5.54 \pm 0.07(2)$ & 5.42 & 1.46 & 0.72 & 1.03 \\
\hline 17 & $\mathrm{COCH}_{3}$ & $6.37 \pm 0.01(2)$ & 6.34 & 2.42 & 0.50 & 0.60 \\
\hline 18 & $\mathrm{C}_{6} \mathrm{H}_{5}^{f f}$ & $5.17 \pm 0.03$ & 7.98 & 4.49 & -0.01 & 0.71 \\
\hline
\end{tabular}

a) Mean \pm standard deviation. Values in parentheses indicate the number of replications.

b) Calculated with Eq. 3 .

c) Unless noted, from Refs. (10) and (11).

${ }^{d)}$ From Ref. (22).

${ }^{e)}$ Estimated from the value of closely related compounds. ${ }^{32)}$

${ }^{f)}$ Not used to derive Eq. 3.

Table 2. QSAR results ${ }^{a)}$

Regression coefficients ${ }^{b)}$

\begin{tabular}{|c|c|c|c|c|c|c|c|c|}
\hline \multirow[t]{2}{*}{ Intercept $^{b)}$} & & & & \multirow[t]{2}{*}{$S^{c)}$} & \multirow[t]{2}{*}{$r^{2 d)}$} & \multirow[t]{2}{*}{$F_{m, n-m-l}{ }^{e)}$} & \multirow[t]{2}{*}{$\left.F_{l, n-m-1} f\right)$} & \multirow[t]{2}{*}{ Eq. } \\
\hline & $\log \mathrm{P}$ & $\sigma$ & $\Delta \mathrm{B}_{1}$ & & & & & \\
\hline $4.610( \pm 0.868)$ & $0.759( \pm 0.255)$ & & & 0.402 & 0.729 & $F_{1,15}=40.366$ & $F_{1,15}=40.366$ & 1 \\
\hline $5.654( \pm 0.748)$ & $0.493( \pm 0.208)$ & $-1.049( \pm 0.487)$ & & 0.262 & 0.893 & $F_{2,14}=58.169$ & $F_{1,14}=21.312$ & 2 \\
\hline $5.502( \pm 0.723)$ & $0.607( \pm 0.238)$ & $-0.822( \pm 0.532)$ & $-0.367( \pm 0.441)^{g)}$ & 0.243 & 0.914 & $F_{3,13}=46.026$ & $F_{1,13}=3.228$ & 3 \\
\hline
\end{tabular}

a) Number of compounds is 17 . Compound $\mathbf{1 8}$ was not used to derive correlation equations.

b) Values in parentheses are $95 \%$ confidence intervals of the regression coefficient and intercept.

${ }^{c}$ Standard deviation of the correlation.

d) Squared value of the correlation coefficient $(r)$.

e) The $F$ ratio between regression and residual variances. $n$ is the number of compounds, and $m$ the number of independent variables, theoretical values being $F_{1,15,0.05}=4.543$ and $F_{3,13,0.05}=3.411$.

f) The $F$ ratio for the addition of each parameter, the theoretical $F$ value being $F_{1,13,0.05}=4.667$.

g) Justified at $90.4 \%$. 


\section{DISCUSSION}

The binding affinity measured with Sf-9 cells was compared with the larvicidal activities against $C$. suppressalis, $S$. exigua and coleopteran L. decemlineata. As shown in Fig. 2, the binding affinity is positively correlated to insecticidal activity against lepidopteran insects, S. exigua and C. suppressalis, with some scattering, but not with that against L. decemlineata. These observations are consistent with the results of our previous studies. ${ }^{10-15)}$

The significance of the $\log \mathrm{P}$ term in Eq. 3 indicates that hydrophobic para-substituents enhance the binding of DBHs to the receptor. Generally, the size of the coefficient of the hydrophobic parameter term, which is about 0.5 , has been taken to mean that ligands would bind to the surface of receptor proteins, while, when it is about 1.0, ligands could be buried in the receptor pocket. ${ }^{23)}$ Therefore, the coefficient (0.607) of the $\log$ P term in Eq. 3 suggests that this series of compounds is not fully buried in the binding pocket. This result is interesting because PonA itself is shown to be buried in the binding pocket. ${ }^{24)}$

A negative coefficient of the $\Delta \mathrm{B}_{1}$ term means that steric repulsion occurs between the para-substituent and receptor as shown in Fig. 3. The minimum width of substituents seems to be decisive to adjust the optimum interaction between receptor and ligand in the vicinity of para-substituents. ${ }^{21)}$ Steric parameters, such as STERIMOL $\mathrm{L}$ and $\mathrm{B}_{5}{ }^{25)}$ and van der Waals volume $\mathrm{V}_{\mathrm{w}}{ }^{26}$ ) did not give any significant correlation.

In our previous QSAR study for the larvicidal activity of the same series of compounds against $C$. suppressalis, steric parameters, $\mathrm{L}$ and $\mathrm{V}_{\mathrm{w}}$, were significant instead of $\mathrm{B}_{1} \cdot{ }^{10,11)}$ The

Table 3. Squared correlation $\left(r^{2}\right)$ matrix for the variables used to derive Eqs. 1-3

\begin{tabular}{lll}
\hline & $\log \mathrm{P}$ & $\sigma$ \\
\hline$\sigma$ & 0.354 & \\
$\Delta \mathrm{B}_{1}$ & 0.122 & 0.032 \\
\hline
\end{tabular}

(A)

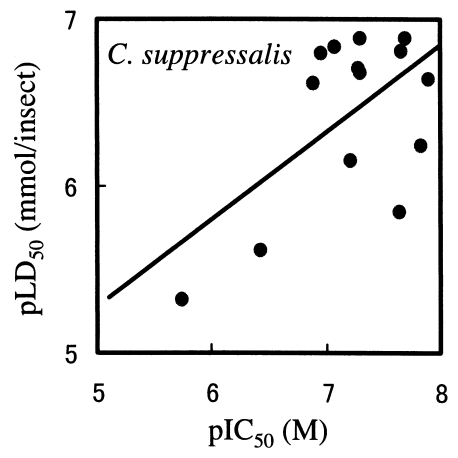

(B)
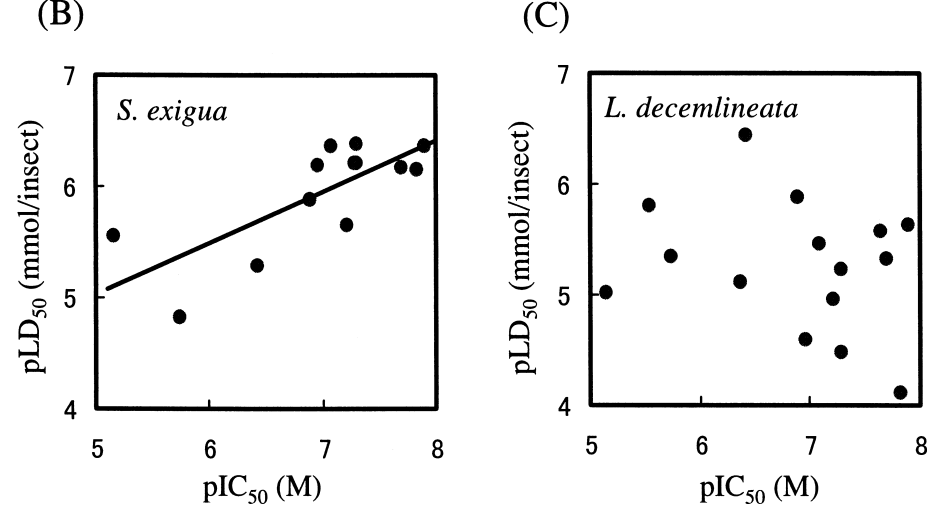

parameter $\mathrm{L}$ represents the length and $\mathrm{B}_{5}$ represents the maximum width of the substituent. ${ }^{21}$ The significance of $B_{1}$, but not of $\mathrm{B}_{5}$ or $\mathrm{L}$, means that, in the receptor binding, the steric repulsion in the para position occurs from the side where their width is minimum. When substituents are rotatable around the axis, they prefer to take a conformation with the minimum energy of repulsion against the receptor wall.

The negative coefficient of the $\sigma$ term in Eq. 3 suggests that perhaps the electron-donating effect of the substituents is favorable in the interaction of the CONH group with the receptor. On the other hands, the requirement of the amide $\mathrm{NH}$ hydrogen for the activity was demonstrated by showing that the activity is lost in $\mathrm{N}$-alkylated compounds. ${ }^{4,27)}$ Recently, Billas et al. performed an X-ray crystal structure analysis of the complex of BYI06830 (Fig. 1) with the ecdysone receptor protein of a lepidopteran insect species, the tobacco budworm Heliothis virescens. ${ }^{24)}$ They showed that the vicinal $\mathrm{CO}$ and $\mathrm{NH}$ groups interact with the guanidinium hydrogen of Arg504 and the phenolic $\mathrm{OH}$ of Tyr408, respectively, in the ligand binding domain of the receptor protein. The size of the coefficient of the $\sigma$ term in Eq. 3, which is close to -1.0 , indicates that perhaps an electron-donating interaction at the $3 \mathrm{rd}$ "bond" position from the benzene ring is critical/rate-determining in the "concerted" interactions. The situation is shown in Fig. 3.

In our previous QSAR for the larvicidal activity of DBHs against $C$. suppressalis, no electronic parameter was significant. ${ }^{10)}$ The most likely reason for the difference from the present result for the "receptor" binding shown as Eq. 3 is the participation of metabolism under larvicidal test conditions. We previously demonstrated that the coefficient of the electronic parameter varies if the metabolic inhibitors are used in the insecticidal ${ }^{28)}$ as well as in the tissue level assay ${ }^{29)}$ of a series of chitin-synthesis-inhibiting benzoylphenylureas. The coefficients of the $\sigma$ term for larvicidal activity with and without an oxidation inhibitor, piperonyl butoxide (PB), were 1.3 and 2.9, respectively. ${ }^{28)}$ A more drastic change in the coefficient was observed for the tissue level assay between activities of a similar set of benzoylphenylureas with and without $\mathrm{PB}^{29)}$ The positive coefficient $(+2.1)$ in the QSAR for the

Fig. 2. Relationship of the binding activity with the larvicidal activity. 


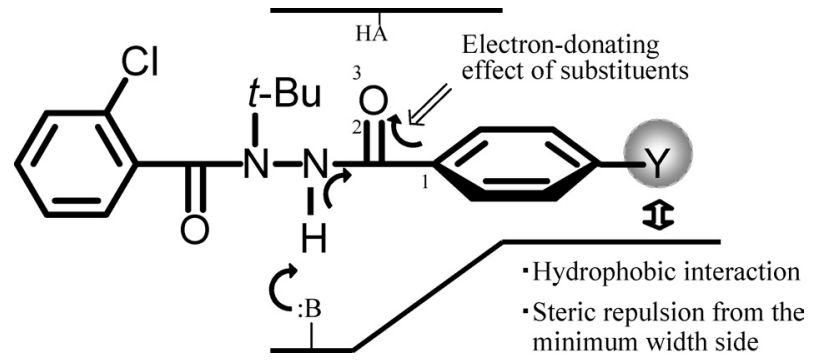

Fig. 3. A possible model of the binding of dibenzoylhydrazines to the receptor.

activity without PB changed to a negative values $(-0.59)$ for the activity with PB. We suggested that electron-withdrawing substituents play a role in depressing the oxidative detoxication and electron-donating substituents are favorable to the intrinsic activity. The negative and positive electronic effects could be cancelled by the metabolism in in vivo QSAR. Similarly, the electron-donating effect of substituents at the B-ring moiety of DBHs would be hidden by metabolic effects in the larvicidal activity assay.

The reason for the very low activity of compound $\mathbf{1 8}$, which behaves as an outlier is not clear at the moment. The supraoptimal length in terms of the STERIMOL L of the phenyl group could not be accepted because the $\mathrm{L}$ value of the $n$-Bu substituent in the most active compound $\mathbf{1 3}$ is 4.11 and close to that of the phenyl group (4.22). The aromaticity and rigidity of the phenyl group might be related to the low activity of compound $\mathbf{1 8}$.

In conclusion, the present QSAR study provided valuable information confirming the ligand-receptor interaction which was disclosed by an X-ray crystal structure analysis. ${ }^{24)}$ In addition to the significance of the hydrophobic interaction, the participation of electronic interaction was clearly demonstrated in this study. The primary sequence of the ecdysone receptor protein of various insects is becoming available. With these sequences, it would be possible to model 3D structures of ligand-binding domains of ecdysone receptors. ${ }^{30,31)}$ With such modeling studies, QSAR could offer important information for the structure-based design of ecdysone analogs.

\section{ACKNOWLEDGMENTS}

We are thankful to Professor Toshio Fujita for carefully reviewing this manuscript. A part of this study was performed in the RI Center of Kyoto University. This investigation was supported in part by grants-in-aid for Scientific Research from the Ministry of Education, Science, and Culture of Japan $(09660117,10161207)$.

\section{REFERENCES}

1) A. C.-T. Hsu: "Synthesis and Chemistry of Agrochemicals II," Vol. 443, ed. by D. R. Baker, J. G. Fenyes and W. K. Moberg, American Chemical Society, Washington DC, pp. 478-490, 1991.

2) K. D. Wing: Science 241, 467-469 (1988).
3) K. D. Wing, R. A. Slawecki and G. R. Carlson: Science 241, 470-472 (1988)

4) A. C.-T. Hsu, T. T. Fujimoto and T. S. Dhadialla: "Phytochemicals for Pest Control," Vol. 658, ed. by P. A. Hedin, R. M. Hollingworth, E. P. Masler, J. Miyamoto and D. G. Thompson, American Chemical Society, Washington DC, pp. 206-219, 1997.

5) G. R. Carlson, T. S. Dhadialla, R. Hunter, R. K. Jansson, C. S. Jany, Z. Lidert and R. A. Slawecki: Pest Manag. Sci. 57, 115-119 (2001).

6) Y. Sawada, T. Yanai, H. Nakagawa, Y. Tsukamoto, Y. Tamagawa, S. Yokoi, M. Yanagi, T. Toya, H. Sugizaki, Y. Kato, H. Shirakura, T. Watanabe, Y. Yajima, S. Kodama and A. Masui: Pest Manag. Sci. 59, 49-57 (2003).

7) T. S. Dhadialla, G. R. Carlson and D. P. Le: Annu. Rev. Entomol. 43, 545-569 (1998).

8) G. R. Carlson: "Green Chemical Syntheses and Processes," Vol. 767, ed. by T. C. Williamson, American Chemical Society, Washington DC, pp. 8-17, 2000.

9) A. R. Horowits and I. Ishaaya: "Insect Pest Management," ed. by A. R. Horowits and I. Ishaaya, Springer, Heidelberg, pp. $1-28,2004$.

10) N. Oikawa, Y. Nakagawa, K. Nishimura, T. Ueno and T. Fujita: Pestic. Biochem. Physiol. 48, 135-144 (1994).

11) N. Oikawa, Y. Nakagawa, K. Nishimura, T. Ueno and T. Fujita: Pestic. Sci. 41, 139-148 (1994).

12) G. Smagghe, Y. Nakagawa, B. Carton, A. K. Mourad, T. Fujita and L. Tirry: Arch. Insect Biochem. Physiol. 41, 42-53 (1999).

13) Y. Nakagawa, G. Smagghe, L. Tirry and T. Fujita: Pest Manag. Sci. 58, 131-138 (2002).

14) Y. Nakagawa, G. Smagghe, S. Kugimiya, K. Hattori, T. Ueno, L. Tirry and T. Fujita: Pestic. Sci. 55, 909-918 (1999).

15) Y. Nakagawa, G. Smagghe, M. Van Paemel, L. Tirry and T. Fujita: Pest Manag. Sci. 57, 858-865 (2001).

16) C. Minakuchi, Y. Nakagawa and H. Miyagawa: J. Pestic. Sci. 28, 55-57 (2003).

17) Y. Nakagawa, C. Minakuchi and T. Ueno: Steroids 65, 537-542 (2000).

18) D. J. Finney: "Probit Analysis," Cambridge University Press, Cambridge, 1952.

19) M. Sakuma: Appl. Entmol. Zool. 33, 339-347 (1998).

20) M. Asao, R. Shimizu, K. Nakao and T. Fujita: "QREG; 2.05 ed. Chemistry Program Exchange,” Kyoto, Japan.

21) A. Verloop, W. Hoogenstraaten and J. Tipker: "Drug Design," Vol. 4, ed. by E. J. Ariens, Academic Press, New York, pp. 165-206, 1976.

22) C. Hansch, A. Leo and D. Hoekman: "Exploring QSAR: Hydrophobic, Electronic, and Steric Constants," ed. by S. R. Heller. American Chemical Society, Washington, DC 1995.

23) T. Fujita: "Comprehensive Medicinal Chemistry," Vol. 4, ed. by C. A. Ramsden, Pergamon, Oxford, pp. 497-560, 1990.

24) I. M. Billas, T. Iwema, J.-M. Garnier, A. Mitschler, N. Rochel and D. Moras: Nature 426, 91-96 (2003).

25) A. Verloop: "Pesticide Chemistry, Human Welfare and the Environment," Vol. 1, ed. by J. Miyamoto and P. C. Kearney, pp. 339-344, 1983.

26) A. Bondi: J. Phys. Chem. 68, 441-451 (1964). 
27) T. Toya, K. Yamaguchi and Y. Endo: Bioorg. Med. Chem. 10, 953-961 (2002).

28) Y. Nakagawa, T. Akagi, H. Iwamura and T. Fujita: Pestic. Biochem. Physiol. 33, 144-157 (1989).

29) Y. Nakagawa, M. Matsutani, N. Kurihara, K. Nishimura and T. Fujita: Pestic. Biochem. Physiol. 43, 141-151 (1992).
30) J. M. Wurtz, B. Guillot, J. Fagart, D. Moras, K. Tietjen and M. Schindler: Protein Sci. 9, 1073-1084 (2000).

31) A. Kasuya, Y. Sawada, Y. Tsukamoto, K. Tanaka, T. Toya and M. Yanagi: J. Mol. Model. 9, 58-65 (2003).

32) T. Sotomatsu, M. Shigemura, Y. Murata and T. Fujita: J. Pharm. Sci. 82, 155-161 (1993). 